Erratum

Orthopäde $2020 \cdot 49: 732$

https://doi.org/10.1007/s00132-020-03921-9

Online publiziert: 8 . Mai 2020

(c) Springer Medizin Verlag GmbH, ein Teil von Springer Nature 2020
C. Berlin · U. Platz · M. Quante · B. Thomsen · M. Köszegvary · H. Halm

Klinik für Wirbelsäulenchirurgie und Skoliosezentrum, Schön Klinik Neustadt, Neustadt in Holstein, Deutschland

\section{Erratum zu: Geringe intraoperative Strahlenbelastung für Skoliosepatienten}

\section{Freihändige Instrumentation mit Vergleich zur Navigation}

\section{Erratum zu:}

Der Orthopäde 2020

https://doi.org/10.1007/s00132-020-

03896-7

Sehr geehrte Leserin,

sehr geehrter Leser,

der oben genannte Beitrag wurde mit einem fehlerhaften Titel publiziert. Bitte beachten Sie den korrekten Titel und Untertitel: Geringe intraoperative Strahlenbelastung für Skoliosepatienten. Freihändige Instrumentation mit Vergleich zur Navigation

Wir entschuldigen uns für den Fehler.

\section{Korrespondenzadresse}

\section{Berlin}

Klinik für Wirbelsäulenchirurgie und

Skoliosezentrum, Schön Klinik Neustadt

Am Kiebitzberg 10, 23730 Neustadt in Holstein,

Deutschland

CBerlin@schoen-klinik.de
Die Online-Version des Originalartikels ist unter https://doi.org/10.1007/s00132-020-03896-7 zu finden. 